\title{
Citizen Science and marine community monitoring by video-cabled observatories: the OBSEA Citizen Science Project
}

\author{
Joaquin del Rio ${ }^{1}$, Jacopo Aguzzi ${ }^{2}$, Alberto Hidalgo ${ }^{1}$, Ikram Bghiel $^{1}$, Antoni Manuel ${ }^{1}$, \\ Valerio Sbragaglia ${ }^{2}$,Francesc Sardà ${ }^{2}$ \\ ${ }^{1}$ Sarti Research Group. Electronics Deparment. Universitat Politecnica de Catalunya (UPC) - Rambla de l'exposició 24, 08800, \\ Vilanova i la Geltrú, Spain. Joaquin.del.rio@upc.edu \\ ${ }^{2}$ Marine Science Institute (ICM-CSIC) - Passeig Marítim de la Barceloneta 37-49, 08003 Barcelona, Spain. jaguzzi@icm.csic.es
}

\begin{abstract}
The Citizen Science refers to the public participation in scientific activities and research projects related with environment and its biodiversity are taking advantage of new technologies such us internet and mobile phones with recording capabilities for an easy data collection and sharing.
\end{abstract}

In this paper, we presented a Citizen Science experience with the OBSEA costal-cabled video-observatory, deployed in western Mediterranean in 2009. A local biodiversity survey is going to be conducted by citizens as generic non-experienced users, highschool students, and amateur divers helping to identify and classify fishes appearing within different digital products such as time-lapse images and footages. Accordingly, we implemented a protocol for the web-based species identification supervised by scientists, in order to evaluate the different performances for each group.

\section{INTRODUCTION}

The concept of marine biodiversity monitoring is evolving thanks to recent technological observational advances. In the marine environment, traditional scientific sampling cruises are becoming too expensive, while highly advanced technological and community based research is becoming more popular. The Citizen Science refers to the public participation in scientific activities and research projects related with environment and its biodiversity are taking advantage of new technologies such us internet and mobile phones with recording capabilities for an easy data collection and sharing. In coastal areas, early marine biodiversity monitoring projects tried to unify research with recreational activities, thanks to scuba divers recruited that completes a survey after a dive. At the same time, other technologically advanced initiatives are prompting the marine observation, as in the case of cabled video-observatories. An open window can be now open at any depth of the continental margin from coastal areas to the deep sea trough underwater video cameras and an internet connection, which allow any user in the planet to analyse short videos of footages for unveil the mechanisms shaping the animal communities.

Cabled multiparametric seafloor observatories connected to the shore for power and real-time data transmission represent a substantial innovation for continental margin and coastal ecosystem monitoring. Most of nowadays deployed cabled observatories bear video cameras [1]. These video-imaging systems may truly represent the first innovative and multifunctional sensor to monitor life activities at different levels of complexity (i.e. from the individual animal, to population, species up to the level of the whole community), provided that automated image analysis is sufficiently developed to classify animals based on differences in shape, texture and color. Fluctuations in video-counted individuals over different time windows (from seconds to decades) can be linked to a wide variety of oceanographic and geologic phenomena, e.g. from cyclic changes in current speed and direction (i.e. internal tides and inertial currents [2]) to more stochastic seismic events.
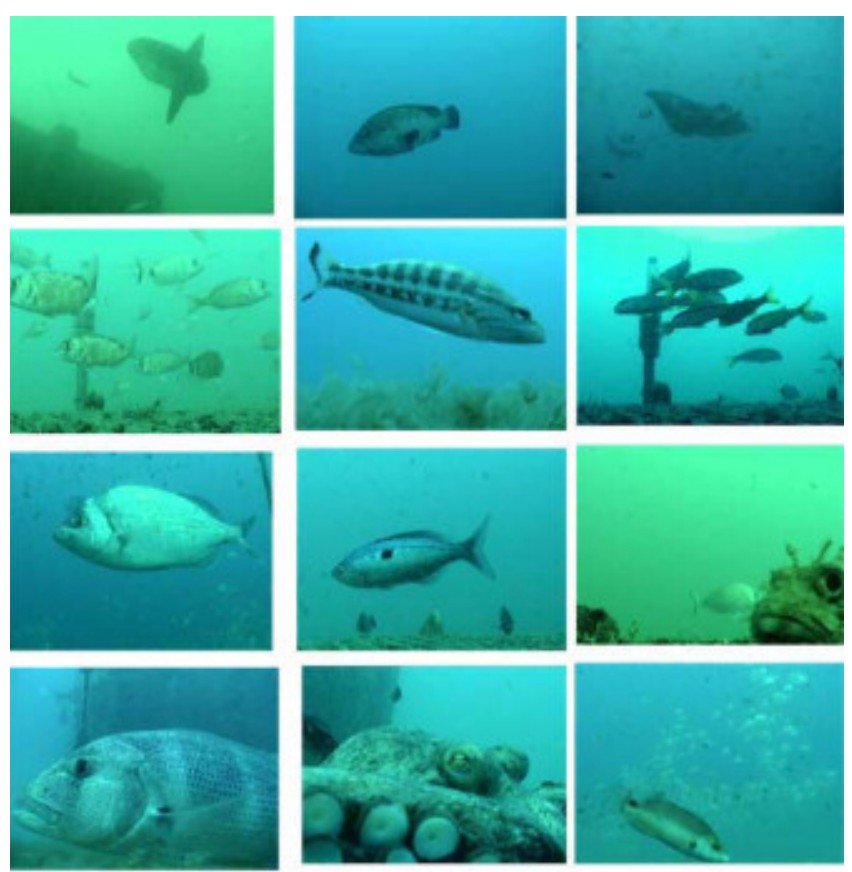

Figure 1. .Snapshots of some of the species present at the Obsea area acquired by Obsea video camera

Allow citizen to help on the production of good images for the adjustment of automatic video analysis algorithms is one of the outcomes of the experiment. 


\section{THE EXPERIENCE}

In this paper is presented a Citizen Science experience with the OBSEA costal-cabled video-observatory, deployed in western Mediterranean in 2009. A local biodiversity survey will be conducted by citizens as generic non-experienced users, highschool students, and amateur divers helping to identify and classify fishes appearing within different digital products such as time-lapse images and footages. Accordingly, we implemented a protocol for the web-based species identification supervised by scientists, in order to evaluate the different performances for each group. An open access web site was designed in a friendly user fashion in order to allow registered users to be connected any time and everywhere. Users' classification performances will be evaluated by tagging options on each selected animal within each video output. A web referenced image library for all local species is used as reference for classification, being constantly updateable by new entries by any user (after supervised validation). Results are discussed considering Citizen Science classification outputs and performances as a reliable tool to improve the efficiency of future automated video-imaging. Manual classification performances may help to transform video cameras into "intelligent" sensors for the autonomous and continuously ongoing monitoring of marine communities a virtually any depth of the continental margin.

The transformation of video cameras into "intelligent" sensors will require the consistent implementation of automated video-imaging in relation to [3][4][5]: $i$. animal motion detection on complex and temporally variable muddy or rocky seabed substrates; ii. Animal' classification, by adopting morphometric-dependent tools (Fourier Descriptors; SIFT). Mathematically transformed and extracted animals profiles will be compared with those of morphological models of reference [6], as obtained by libraries of images in which animals of each species appear from all angles of vision. In these libraries, animals are manually classified by trained operators and new species can be continuously added (i.e. the supervised machine-learning approach)[4]. The profile of "library" animals can also be extracted, obtaining an averaged morphological model for comparison with each newly identified individual. That comparison will be carried out by multivariate statistics (i.e. K-Nearest Neighbour and Partial Least Square Discriminant Analysis) [7].

\section{CitiZEN CONTRIBUTION}

Citizen will participate on the experience through a web site as can be shown in figure 3. The user navigation trough the web portal user interface is structured in 4 phases as follows:

I. Phase 0: first time registration of the user in the web portal.

II. Phase 1: selection of the video frame where the animal is better recognized: options for training or research.
III. Phase 2: identification of the animal.

IV. Phase 3: select options for the picture sending for scientific validation.

The initial phase, Phase 0 , aims to register the user as a customer web portal and get their personal information to allow statistics of use of the portal, and knowledge of the marine environment by different ages, geographic area, education or professional dedication, etc... Information about its registration is sent to the user by email. Main steps for phase 0 are depicted in figure 2 .

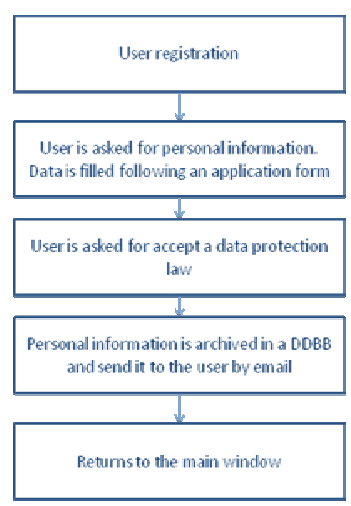

Figure 2. . Main steps in phase 0 for user registration

After first visit of the user and registration process is completed, next visits to the portal the user will authenticate with its personal login and password. Phase 1 is dedicated to obtain an image wherein the animal is best presented. The steps of this phase are depicted on figure 4 . The user has the possibility to start with a training option where previously acquired video is shown to the user. The previously acquired video is selected in order to show animals recognized previously by the scientific team.

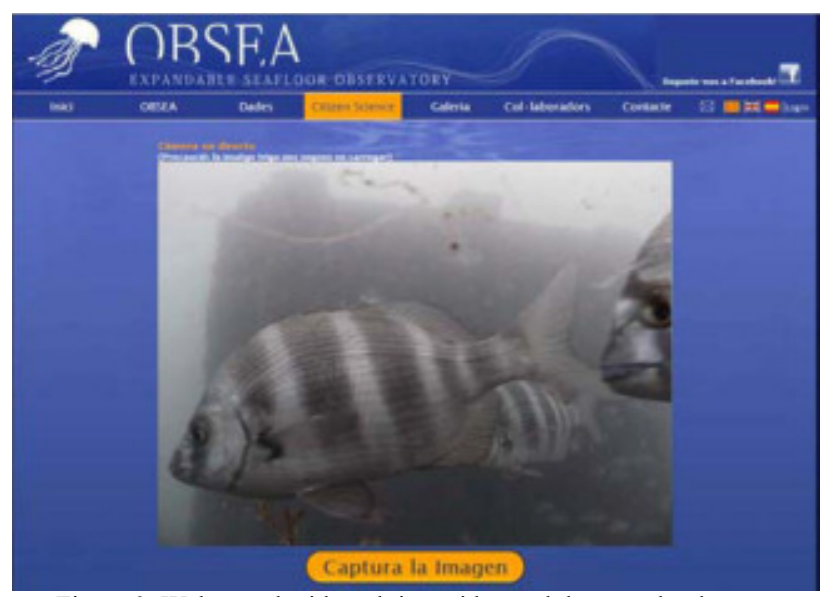

Figure 3. Web portal with real time video and the snapshot button.

Once the better image is selected, phase 2 is dedicated to the identification of the animal. A list of different species present in the area, with photos as depicted in figure 1, are presented to 
the user in order he can identify its capture. Table 1 shows a full list of species. The identification is associated with a percentage. The user can assign a $100 \%$ for specie if he is totally sure, or distribute a percentage between species. These steps are depicted in figure 5. All of this work is archived for later access and review by the user.

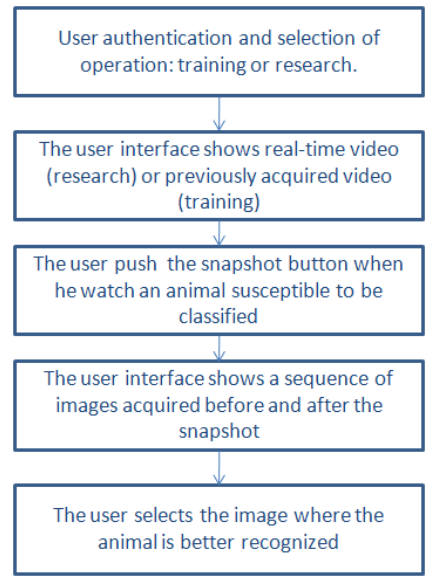

Figure 4. . Main steps in phase 1 for the animal picture selection.

Once the user has identified the animal, he can choose to send the classification for a scientific review or just archive its work for a later review. After scientific review, the user is informed about its success. Different rankings will be done between users depending on its success classifying species.

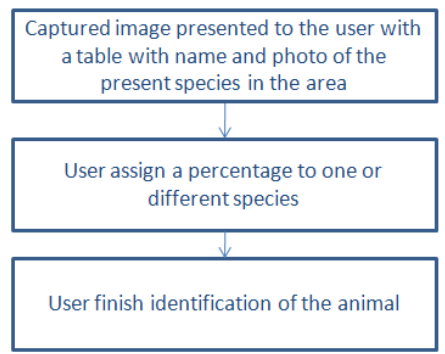

Figure 5. . Main steps in phase 2 for the identification of the animal.

\section{CONCLUSIONS}

Access to the web portal can be done at www.obsea.es . During February 2013 the citizen science experiment will start. Statistics and rankings are going to be generated. Best images will allow the improvement of automatic video analysis algorithms.

\section{ACKNOWLEDGMENT}

This work was supported in part by the Generalitat de Catalunya (Departament d'Economia i Coneixement), regional funded project: Visió submarina: un entorn per l'aprenentatge i l'experimentació (contract number 2012ACDC 00060).
Table 1. List of some common species present in the Obsea area

\begin{tabular}{|l|l|}
\hline Linnaean name & Common Names \\
\hline Boops boops (Linnaeus, 1758) & Bogue \\
\hline Loligo vulgaris (Lamarck, 1798) & European squid \\
\hline Spondyliosoma cantharus (Linnaeus, 1758) & Black seabream \\
\hline Chromis chromis (Linnaeus, 1758) & Damsel fish \\
\hline Seriola dumerili (Risso, 1810) & Greater amberjack \\
\hline Conger conger (Linnaeus, 1758) & Conger eel \\
\hline Sciaena umbra (Linnaeus, 1758) & Brown meagre \\
\hline Dentex dentex (Linnaeus, 1758) & Common dentex \\
\hline Coris julis (Linnaeus, 1758) & Mediterranean rainbow wrasse \\
\hline Scorpaena porcus (Linnaeus, 1758) & Black scorpion fish \\
\hline Diplodus annularis (Linnaeus, 1758) & Annular sea bream \\
\hline Gobius vittatus (Vinciguerra, 1883) & Striped goby \\
\hline Symphodus melanocercus (Risso, 1810) & wrasse \\
\hline Symphodus tinca (Linnaeus, 1758) & East Atlantic peacock wrasse \\
\hline Mobula mobular (Bonnaterre, 1788) & Devil fish \\
\hline Mullus barbatus Linnaeus, 1758 & Red mullet \\
\hline Diplodus puntazzo (Walbaum, 1792) & Sharpnout seabream \\
\hline Epinephelus marginatus (Lowe, 1834) & Dusky grouper \\
\hline Oblada melanura (Linnaeus, 1758) & Saddled bream \\
\hline Pagrus pagrus (Linnaeus, 1758) & Common seabream \\
\hline Mola mola (Linnaeus, 1758) & Ocean sunfish \\
\hline Octopus vulgaris (Cuvier, 1797) & Common Octopus \\
\hline Diplodus sargus (Linnaeus, 1758) & White seabream \\
\hline & \\
\hline
\end{tabular}

\section{REFERENCES}

[1] Favali, P., Beranzoli, L., D’Anna, G., Gasparoni, F., Marvaldi, J., Clauss, G., Gerber, H.W., Nicot, M., Marani, M.P., Gamberi, F., Millot, C. \& Flueh, E.R. 2006b. A fleet of multiparameter observatories for geophysical and environmental monitoring at seafloor. Annals of Geophysics 49, 659-680.

[2] Aguzzi, J., Costa, C., Furushima, Y., Chiesa, J.J., Company, J.B., Menesatti, P., Iwase R. \& Fujiwara, Y. 2010. Behavioural rhythms of hydrocarbon seep fauna in relation to internal tides. Marine Ecology Progress Series 418, 47-56

[3] Menesatti P., Costa C., Paglia G., Pallottino F., D'Andrea S., Rimatori V., Aguzzi J. 2008. Shape-based methodology for multivariate discrimination among Italian hazelnut cultivars. Biosyst. Eng. 101:417-424

[4] Aguzzi J., Manuél A., Condal F., Guillén J., Nogueras M., Del Río J., Costa C., Menesatti P., Puig P., Sardà F., Toma D., Palanques A. 2011. The new SEAfloor OBservatory (OBSEA) for remote and long-term coastal ecosystem monitoring. Sensors-Basel (Instruments and Instrumentation) 11: 5850-5872

[5] Aguzzi J., Manuél A., Condal F., Guillén J., Nogueras M., Del Río J., Costa C., Menesatti P., Puig P., Sardà F., Toma D., Palanques A. 2011. The new SEAfloor OBservatory (OBSEA) for remote and long-term coastal ecosystem monitoring. Sensors-Basel (Instruments and Instrumentation) 11: $5850-5872$

[6] Pulcini D., Costa C., Aguzzi J., Cataudella S. 2008. Light and shape: a contribution to demonstrate morphological differences in diurnal and nocturnal Teleosts. J. Morphol. 269: 375-385.

[7] Aguzzi J., Costa C., Menesatti P., Fujiwara Y., Iwase R., RamirezLlorda E. 2009. A novel morphometry-based protocol of automated videoimage analysis for species recognition and activity rhythms monitoring in deep-sea fauna. Sensors 9: 8438-8455 